\title{
The Implementation of Free Route Airspace (FRA) in Slovakia
}

\section{Juraj Vagner ${ }^{1 *}$, Miroslava Ferencová ${ }^{1}$}

\author{
${ }^{1}$ Technical University of Košice, Košice, Slovak Republic \\ *Corresponding author: Department of Flight Preparation, Faculty of Aeronautics, Rampová 7, 04121 Košice, Slovak \\ Republic, Email: juraj.vagner@tuke.sk
}

\begin{abstract}
Replacing the conventional air traffic service (ATS) routes by Free Route Airspace (FRA) in every European state will be mandatory as from the 1st of January 2022. The article is dealing with the FRA in Slovak airspace as the implementation there has already started. The information concerning the on-going FRA projects in Slovakia currently in place are provided along with the planned expansion of south-east European night cross-border FRA operations within CTAs of Bratislava, Bucharest, Budapest and Sofia - SEEN FRA (leading off from Aeronautical Information Circular - AIC A3/18). Following already implemented cross border FRA in Europe, the article also provides a possible way for extension of such kind of the airspace in line with the rules and safety requirements that need to be also taken into account.
\end{abstract}

\section{Keywords}

Slovak airspace; FRA projects in Slovakia; Cross Border FRA operations; SEEN FRA operations; Proposed extension within FAB CE

\section{Introduction}

Following the article "Basic Terminology in Free Route Airspace" issued in Aeronautica XVII 1/2017 (ISBN: 978-83-60617-49-

6), the current article is linked as a continuation of the topic. In the previous article, we have addressed the basic terms concerning FRA. This paper will provide a brief description of European approach towards FRA described in Chapter 2 and consequently, more information regarding the situation in Slovakia and possible future evolution will be provided as well. The implementation of FRA has already started in Slovak airspace with the Aeronautical Information Circular (AIC) A01/16 [1]. In the article, we will focus on the current FRA projects agreed between EUROCONTROL and LPS SR, š.p. that are currently in place. [2] For better imagination, the description of the projects will be supported by the picture demonstration. Another AIC that was issued in relation to FRA in Slovakia was the Aeronautical Information Circular (AIC) A3/18 [3]. The purpose was to provide notification to Aircraft Operators (AOs) and background information concerning the planned expansion of SEEN FRA area. Based on this information and the Cross Border FRAs already successfully implemented in Europe, the third chapter will provide the possible way in which Slovak airspace could be extended, taking also into account different factors.

\section{FRA Evolution}

In 2007, a number of States, ANSPs (Air Navigation Service Providers) and FABs (Functional Airspace Blocks) have pro- 
posed a development towards the implementation of FRA with the purpose of the transition from a fixed route network to direct routes [4]. In 2008, this development and implementation were included in the Flight Efficiency Plan developed cooperatively between IATA (International Air Transport Association), CANSO (Civil Air Navigation Services Organisation), and EUROCONTROL (European Organisation for the Safety of Air Navigation). EUROCONTROL coordinates the development and implementation of full Free Route operations for a large number of ACC (Area Control Center) in Europe. According to the European Commission's regulation 716/2014, the implementation of free routes for each European country will be mandatory above 9000 meters by $1^{\text {st }}$ January 2022.

\section{Situation in Slovak Airspace}

This Chapter is dedicated to a brief description of Slovak airspace in terms of possibilities to fly. While flying over Slovakia, the aircraft can fly using ATS routes or DCTs depending on FL.

The flights in the airspace below FL 245 are using ATS routes. That was decided due to the fact that many military (and other temporarily activated) areas where the flights cannot enter may restrict or limit the DCT operations.

The flights in the airspace above FL 245 are using DCTs. The initial operations with DCTs started on the $28^{\text {th }}$ April 2016 and were announced by the AIC A1/16. This DCT's implementation has been the 1st step of implementing FRA in Bratislava CTA.

\subsection{FRA Projects in Slovakia}

The implementation of current FRA projects in Slovakia will allow the flights to fly across the airspace consisting of 2 or more states without referring to the national or operational boundaries. This is called Cross border FRA operations. It all started in spring 2017 when ACC Bratislava has been invited to join Hungary, Romania and Bulgaria (SEEN FRA) during the night operations. Slovakia accepted the invitation. After implementing such operations, it will be possible to enter the SEEN FRA in Bulgaria using FRA Entry Point and to leave the same airspace in Slovakia using FRA Exit Point. The background information concerning the planned expansion is included in the AIC A 3/18.

The expanded SEEN FRA airspace will bring the optimization of the flight operations in a large volume of airspace. This expansion will also bring operational, environmental and cost benefits. [3]

The figure 1 represents the SEEN FRA area. [3]

The FRA on-going projects in Slovak airspace are the following: [5]

\section{SEENFRA+BRA}

- The aim of this project is to unite FRABRA to SEENFRA and to implement night cross-border FRA (23:00-05:00 UTCW) between Slovakia, Hungary, Romania and Bulgaria;

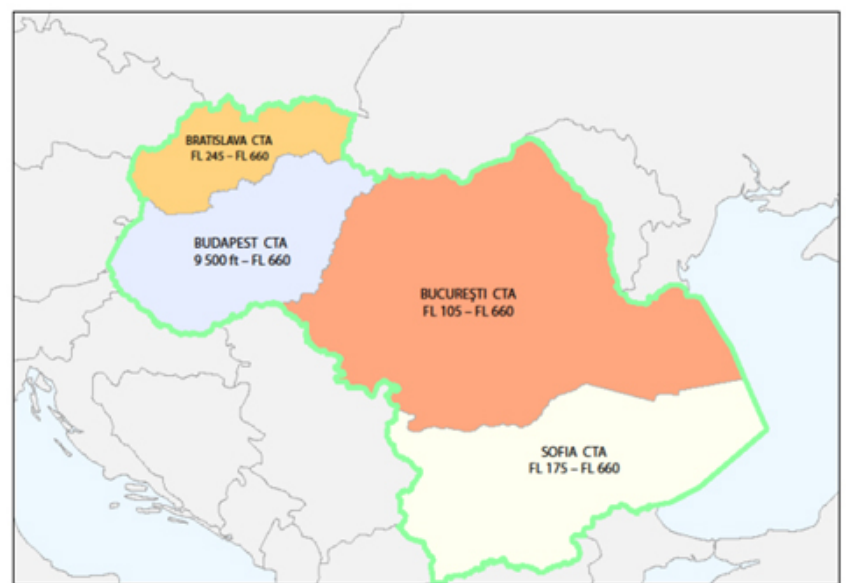

Figure 1. SEEN FRA area

- This project is already ongoing with the planned start of operations in December 2018 (AIRAC 13).

\section{BRAFRA}

- The aim of this project is to implement H24 FRA in the area of responsibility of Bratislava ACC above FL245;

- The planned start of the operations is from March 2019 onwards.

Each of the projects defined above has its own already agreed steps which are described below in separated subchapters.

\subsubsection{SEENFRA+BRA}

Starting from AIRAC 13/18 it is expected to implement SEEN FRA operations in Bratislava CTA. This will result in the cooperation of Slovakia, Hungary, Romania and Bulgaria. This implementation will be different during the day (05002300 UTCW) and during the night (2300-0500 UTCW).

During the day (0500-2300 UTCW) flights in Slovakia will use DCTs in Bratislava FIR. DCTs will be used from FL245 above; below FL245 conventional ATS Route Network will remain. The figure 2 represents the red lines which are illustrating these DCTs.

During the night (2300-0500 UTCW) the situation will change. It is described below and depicted in 3.

SEENFRA operations will be implemented in Bratislava CTA, Budapest CTA, Bucharest CTA and Sofia CTA, therefore flights will be able to fly using FRA Significant Points without any references to the national boundaries. Flights will remain the subject of ATC. The vertical limits of expanded SEEN FRA area will be following: Budapest CTA: $9500 \mathrm{ft}-$ FL 660; Bucharest CTA: FL105 - FL 660; Sofia CTA: FL175 - FL 660; Bratislava CTA: FL245 - FL 660. 


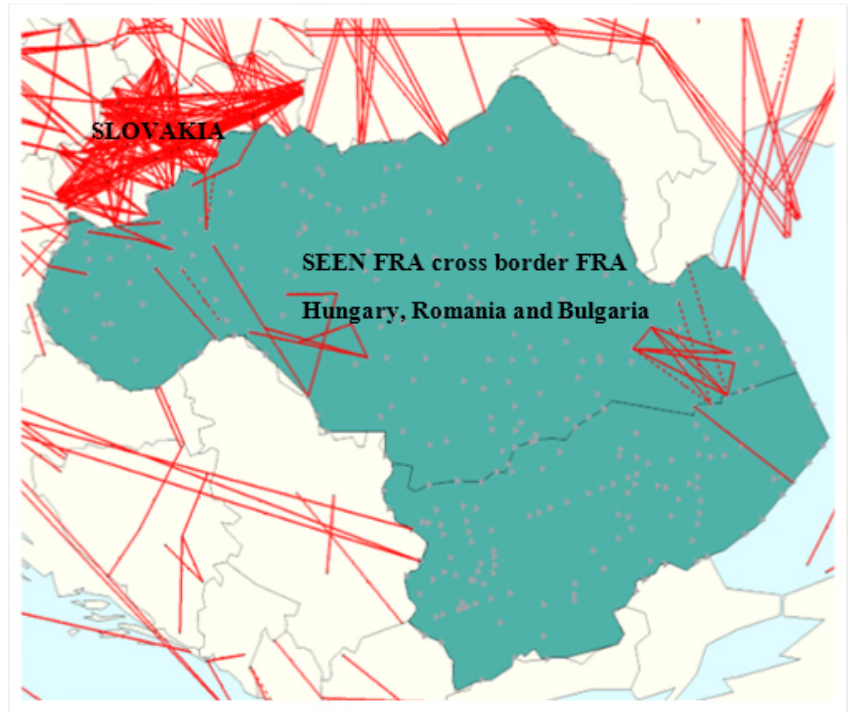

Figure 2. Daily period (0500-2300 UTCW), December 2018 - March 2019 [5]

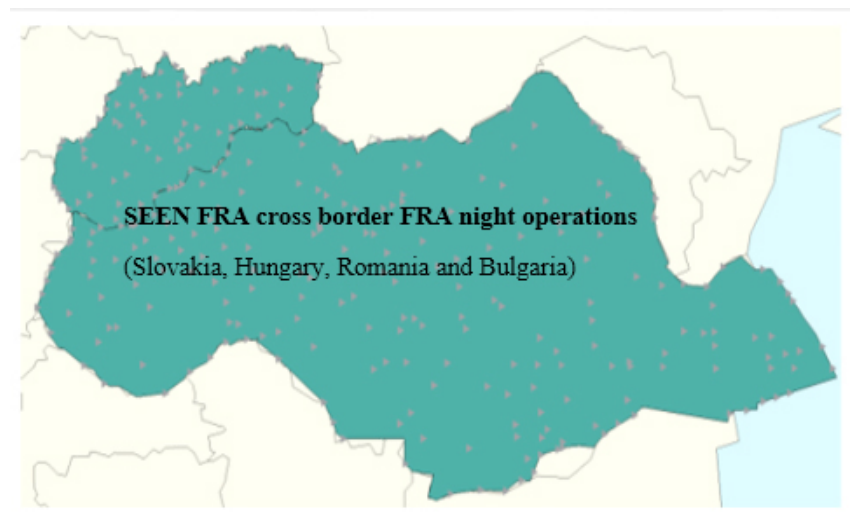

Figure 3. Night period (2300-0500 UTCW), December 2018 - March 2019 [5]

\subsubsection{BRAFRA}

BRAFRA - the second FRA project is planned to be implemented maximum 3 AIRAC cycles later (starting from March 2019). The difference is that the situation during the day will change in Slovakia. DCTs will not be used anymore. In the area of responsibility of Bratislava ACC, from FL 245 above the FRA with intermediate points will be implemented (as depicted on the fig. 4). The airspace below FL245 will remain operated by ATS routes. The night situation will remain the same, i.e. SEEN FRA cross border operations will remain in Bratislava CTA during the night (Fig. 3).

\subsection{The proposed way forward [6]}

The proposal for the way forward is based on cross border FRA that are already implemented and also on the benefits from this cooperation.

In our point of view, the main aim of FRA is to join as much FIR as possible. It was proved that FRA provides more benefits when it is extended to as many FIRs as possible.

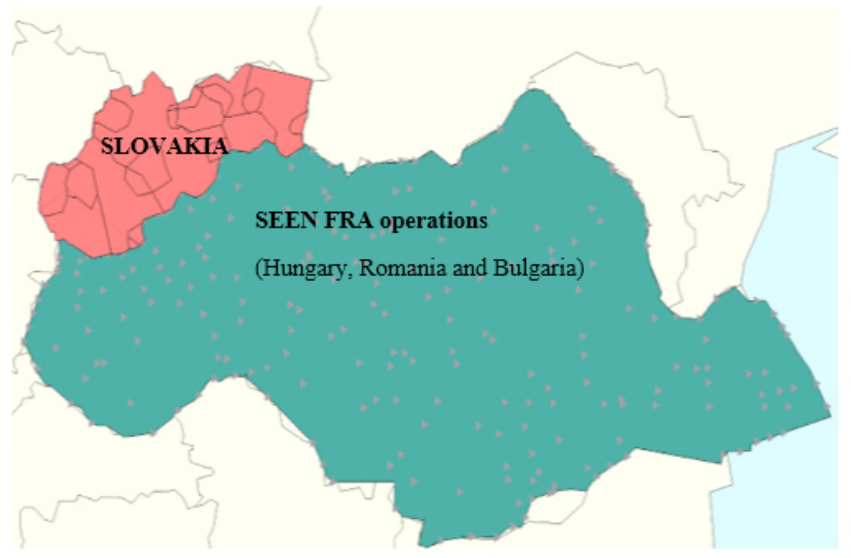

Figure 4. Daily situation (0500-2300 UTCW/0400-2200 UTCS), March 2019 onwards [5]

Therefore, our idea would be to consider FAB CE (Functional Airspace Block Central Europe) as 1 big FIR where flights would fly only using FRA Significant Points without any references to the national boundaries.

This would allow seamless integration of FRA volumes of FAB CE states; enable users preferred trajectories in a large area regardless of FIR borders; users would be able to fly based on the simplified flight plans.

FAB CE consists of the following states - Slovakia, Bosnia $\&$ Hercegovina, Croatia, Czech Republic, Hungary, Slovenia and Austria. This airspace covers more than 529,000 km $\hat{2}$, and it is split into 63 airspace sectors under the responsibility of 8 area control centers (ACCs).

The FAB CE is currently covering 4 successfully implemented Cross Border FRA:

1. SEEN FRA - Hungary, Romania and Bulgaria night time FRA;

2. SAXFRA - Austrian -Slovenian Cross Border FRA;

3. SEAFRA - South-East Axis FRA - Croatia, Serbia and Montenegro, Bosnia and Hercegovina;

\section{SECSI FRA - SAXFRA + SEAFRA}

Slovakia will become a part of SEEN FRA at night time. It will join Hungary, Romania and Bulgaria during their night operations. The important note is that only Hungary and Slovakia are states of FAB CE, so this connection will be the union of 2 FABs.

From the states of FAB CE there is the only Czech Republic, which is not running FRA operations yet. Therefore, the proposal for the future is to implement cross border FRA between Hungary, Slovakia and Czech Republic in order to make one big area. This area would be characterized by entry/exit point without reference to the national boundaries, AoR. The flights would be able to fly within these 3 states without any boundaries restrictions. This connection would allow having all states covered by cross border FRA activities. 
The connection of 2 cross border areas has already started on 1st of February 2018, with the unification of SAXFRA and SEA FRA resulting in SECSI FRA. Although this cross border FRA is not active for a long time, it is already very successful. There already have some calculated potential savings which are up to $1.940 \mathrm{NM}$ in flight distance per day, 285 minutes in flight time, a reduction in fuel consumption of $8,000 \mathrm{~kg}$ and a reduction in $\mathrm{CO} 2$ emissions of $25,500 \mathrm{~kg}$.

Having SECSI FRA successfully implemented, we can see that the connection of 2 cross border FRA is possible. Therefore, we would propose to join the FRA between Slovakia, Czech Republic and Hungary to SECSI cross border FRA. Connecting this airspace to SECSI cross border FRA, it would be achieved that states are covered by one big airspace volume. The flights could fly across this airspace, crossing different countries only using entry/exit points on the boundaries of this cross border FRA connection.

Running this kind of airspace would need further detailed coordination - the value of FL, who is responsible for the control, etc.

The most important coordination is between states, as every state is responsible to decide to implement FRA from its own defined FL. For this case, we are considering 2 different options:

1. the flights in the cross-border FRA are on the same FL;

2. the flights in the cross border FRA are operated on FLs as decided by states;

While the first option would require the agreement regarding the value of FL between all states, the second one would require the procedures that are allowing a smooth transition from one FL to another and should be precisely defined.

Another important thing is to decide how this airspace will be controlled. As FRA is a very popular project, each country would be more than happy to take a control of such airspace. This point should be also coordinated and analyzed.

Impact on the air traffic controllers needs also be taken into account. As a prerequisite, there is a required training needed, adaptation to different situations, completely changed planning, used methods etc. This has to be done in order to ensure all safety aspects of the air traffic.

\section{Discussion}

As Free Route Airspace (FRA) is a new project in the sense that there has not been any project like this before, is more than needed to maintain a high level of safety, follow the fixed rules and the procedures. On one side, this leading position can be an advantage but on the other side, there are many unknown problems which may appear before/during/after the implementation. As some European states have already implemented full or night FRA operations, remained states (which are still not running FRA operations) can use the problems discovered as some lessons learned in order to not make the same mistake twice. Concerning Slovak airspace, the authors believe that the cooperation with other states will bring more benefits for Slovakia. Therefore, our proposal was to extend it further and support the idea of Cross Border FRA. The good point is that in European airspace there are already few successfully implemented Cross Border FRAs so we have ideal examples how it works, what kind of benefits it may bring and also the situations which we should beware of.

\section{Conclusion}

The article provided the summary of the FRA on-going projects that are already agreed between LPS SR, š.p. and EUROCONTROL. The planned expansion of south-east European night cross-border FRA operations within CTAs of Bratislava, Bucharest, Budapest and Sofia (SEEN FRA) is closely connected with these projects. The implementation of SEEN FRA operations in Slovakia will first start during the night night FRA (between Slovakia, Hungary, Romania and Bulgaria) which will allow a smoother transition to full FRA H24. The step forward will be in force from March 2019, implementing FRA operations in Bratislava CTA during daily operations while during night Slovakia will remain joined to SEEN FRA. Later on, the article provided the current situation of Cross Border FRA currently implemented in FAB CE. Based on the experience and studies of those areas, we have proposed the possible way in which Slovakia could cooperate together with Czech Republic and Hungary in the future.

\section{Acknowledgments}

The detailed description of the on-going FRA projects along with the supporting pictures was provided by the Head of ATM Planning and Procedures Department, LPS SR š.p.

\section{References}

[1] Aeronautical Information Services of the Slovak Republic. Aic a 1/16 - free route airspace bratislava (frabra) with effect from airac 28 apr 2016 ufn, 2016. URL https : / / aim.lps.sk/web/ ? fn=203\&lng=en\&sess= CfCqLTRN 75KsoHOI 9P zAx 0 gut 4R6sbg j I HGCGCBE \& type $=3 \&$ serie $=$ A.

[2] FAB CE. Airspace alliance, 2018. URL http://www . fab-ce.eu/airspace/free-route.

[3] Aeronautical Information Services of the Slovak Republic. Aic a 3/18 - planned expansion of south east european night cross-border free route airspace operations within ctas of bratislava-bucureŞti-budapestsofia (seen fra), 2018. URL https://aim.lps. sk/web/alone.php? fn=204\&lng=en\&sess= dPp 6QLx15srBVr2LD 9oe8h0 JbeSMZV7xJBCFHEAD \& doc $=3941$.

[4] EUROCONTROL. European route network improvement plan: Part 1 european airspace design. 
[5] Jan Marco. Route network development in bratislava fir, 2018. URL https://www.eurocontrol. int/sites/default/files/events/ presentation/17-eurocontrol-fraworkshop-2018-marco.pdf.

[6] Miroslava Ferencová. The implementation of Free Route Airspace (FRA) in Slovakia. Technical University of Košice, Faculty of Aeronautics, Košice, 2018. 